\title{
Culture technique, Culture d'innovation : présentation générale
}

\section{Technical culture and culture of innovation: a general overview}

\author{
Marianne Chouteau $^{1}$, Joëlle Forest ${ }^{1}$, Céline Nguyen $^{1}$ \\ 1 EA 4148 - S2HEP, Université de Lyon, marianne.chouteau@insa-lyon.fr, joelle.forest@insa-lyon.fr, \\ celine.nguyen@insa-lyon.fr
}

\begin{abstract}
RÉSUMÉ. L'innovation apparait par ailleurs comme étant la meilleure solution pour faire face aux grands problèmes contemporains auxquels les sociétés actuelles sont confrontées et au rang desquels figurent le réchauffement climatique, le vieillissement de la population, la raréfaction des ressources etc. Ce numéro spécial est structuré en trois temps. Dans un premier temps il revient sur l'histoire des concepts de culture technique et culture d'innovation et de leur diffusion dans la société. La deuxième partie illustre ces concepts au travers l'histoire d'objets particuliers, celle du vélo et du numérique. La dernière partie de ce numéro est quant à elle centrée sur l'action et présente d'une part ce que recouvre la culture d'innovation dans les organisations et, d'autre part la culture technique comme enjeu de formation.

ABSTRACT. Innovation appears to be the best solution to deal with the major contemporary problems facing today's society, including global warming, an aging population, scarcity of resources, and so on. This special issue is structured in three stages. In a first step, hit reviews the history of the concepts of technical culture and innovation culture and their diffusion in society. The second part illustrates these concepts through the history of particular objects, that of cycling and digital technology. The last part of this issue focuses on action and on the one hand presents the culture of innovation in organizations and, on the other hand, technical culture as a training challenge.

MOTS-CLÉS. Culture technique, innovation, culture d'innovation, Histoire.

KEYWORDS. Technical culture, innovation, innovation culture, History.
\end{abstract}

\section{La question}

Si durant des siècles l'innovation a été vue comme un danger, un élément perturbateur du "bon » fonctionnement des sociétés, force est de constater qu'elle est désormais largement valorisée au sein des sociétés occidentales.

Depuis les travaux pionniers de Joseph Schumpeter, nombre de théoriciens ont effectivement confirmé le rôle central de l'innovation dans la dynamique économique. A suivre le prix Nobel d'économie Edmund Phelps, l'état actuel de l'Europe serait d'ailleurs imputable au déclin de l'innovation en Europe. Articuler innovation et croissance permet de s'émanciper, comme le souligne Philippe Aghion, de la conception d'une croissance fondée sur l'accumulation du capital (modèle néoclassique), et offre une vision plus optimiste du futur, l'innovation constituant alors le moteur d'une croissance qu'il qualifie de durable.

L'innovation apparait par ailleurs comme étant la meilleure solution pour faire face aux grands problèmes contemporains auxquels les sociétés actuelles sont confrontées et au rang desquels figurent le réchauffement climatique, le vieillissement de la population, la raréfaction des ressources etc. Ces défis sont immenses et appellent des solutions innovantes. Ils sont à l'origine d'une injonction croissante à innover. Il semble alors qu'une des voies privilégiées depuis quelques années passe par le développement d'une culture d'innovation. L'entreprise Apple est souvent citée comme exemple d'une société qui réussit car elle possède une culture d'innovation. Mais celle-ci est-elle suffisante pour apporter des solutions à ces grands défis contemporains? N'avons-nous pas également besoin de posséder une culture technique? 
En effet, et curieusement, alors que l'on parle beaucoup de culture d'innovation, la culture technique reste la grande absente lorsqu'il s'agit d'innovation $\mathrm{Si}$ la culture scientifique et technique est convoquée dès lors qu'il d'agit de penser notre rapport aux sciences et aux techniques, au progrès ou à la recherche, il n'en est rien lorsqu'il s'agit d'innovation, comme si l'innovation et la technique étaient culturellement étanches. En quoi sont-elles donc séparées ? Pourquoi ce constat ? Et enfin, pourquoi faudrait-il mettre de la culture dans la technique et l'innovation?

Dans le présent numéro nous partirons de ces constats et nous interrogerons par conséquent sur l'enjeu de convoquer la question de la culture technique et d'innovation dans le débat. Grâce à la diversité des points d'entrée et des disciplines mobilisées, les contributeurs parviendront à éclairer les enjeux autour des concepts de culture technique et culture d'innovation mais aussi autour de l'articulation possible entre ces deux cultures.

\section{La structure}

Pour ce faire, ce numéro spécial est structuré en trois temps. Dans un premier temps il revient sur l'histoire des concepts de culture technique et culture d'innovation et de leur diffusion dans la société. La deuxième partie illustre ces concepts au travers l'histoire d'objets particuliers, celle du vélo et du numérique. La dernière partie de ce numéro est quant à elle centrée sur l'action et présente d'une part ce que recouvre la culture d'innovation dans les organisations et, d'autre part la culture technique comme enjeu de formation.

L'historienne des techniques Anne-Françoise Garçon ouvre, en effet, ce volume par un article consacré à la lente émergence de la culture d'innovation à l'occidentale. Derrière ce constat se cache en réalité la difficile objectivation de la technique d'abord, puis de l'innovation. Si la prise de conscience de la technique s'est faite dès le $\mathrm{XVI}^{\mathrm{e}}$ siècle, pour autant, elle ne s'est pas accompagnée d'une culture d'innovation. Plusieurs raisons à cela: l'innovation fut tout d'abord crainte car synonyme de remise en cause de l'ordre établi .Elle a véhiculé des peurs empêchant justement la culture d'innovation de se développer mais pas l'innovation. Une autre raison est le développement de cultures opératoires en lieu et place d'une culture d'innovation. L'auteure nous montre alors que la culture d'innovation occidentale faite proche d'une culture «tableau de bord» s'est finalement développée fin $\mathrm{XIX}^{\mathrm{e}}$, début $\mathrm{XX}^{\mathrm{e}}$ siècle jusqu'à recouvrir une culture technique chez les concepteurs contemporains.

Marianne Chouteau, Joëlle Forest et Céline Nguyen s'attachent à montrer l'importance d'une culture technique pour comprendre le sens donné à la technique et au monde qu'elle construit. Elles développent l'idée selon laquelle la culture d'innovation, aujourd'hui telle qu'elle est pensée, empêche le développement d'une culture technique agissante et réflexive qui permettrait d'intégrer la technique dans un ensemble symbolique et culturel. Pour ce faire, elles établissent une définition de la culture technique en s'appuyant sur des auteurs tels que Bruno Jacomy, Yves Deforge, Philippe Roqueplo, Jocelyn De Noblet ou Gilbert Simondon. Les auteures mettent en évidence le caractère réflexif et agissant de la culture car elle doit mettre en relation la technique et le monde environnant. Pourtant, elles précisent également que cette culture technique peine encore aujourd'hui à se développer alors qu'elle permettrait à tout à chacun de sortir de la simple posture de consommateurs, de se prémunir de l'aliénation à la technique et enfin de penser aux grands défis techniques de demain. En ce sens, elles soulignent le fait que malgré les bouleversements contemporains - artificialisation du monde, raréfaction de l'énergie, etc. - la question de la technique ne semble que très peu posée au bénéfice d'une injonction à l'innovation sans cesse renouvelée. Par là même, elles affirment que c'est justement la culture d'innovation qui fait écran à une culture technique pourtant nécessaire.

L'historien Yves Lequin propose d'analyser l'histoire du vélo, de la draisienne née il y a exactement deux siècles (en 1817), aux vélos actuels dont l'engouement est indiscutable. C'est par le biais de cet objet somme toute banal qu'il nous invite à militer pour l'incorporation de la culture technique dans 
l'activité de conception, centrale dans le processus d'innovation. En effet, le décryptage précis et chronologique de l'évolution du vélo montre que le processus d'innovation est d'une part complexe et d'autre part fait de constants allers et retours à l'environnement social, culturel, économique et politique. Ainsi, l'auteur démontre que le vélo (ou ses versions antérieures) a répondu à différents types de besoins : il a remplacé le cheval, permis de gagner du temps, permis aux snobs de parader, aux vacanciers et ouvriers de se déplacer... et ce faisant que l'innovation contient une "part sociale » importante. Cette part sociale est incarnée dans les usages qui ont évolué dans le temps en même temps que le vélo a connu des améliorations techniques. Elle est aussi faite de peurs ou de freins " moraux » comme le risque de déshumanisation un temps évoqué. On appréciera donc dans ce texte tout d'abord la richesse des preuves tangibles de la part sociale des innovations mais aussi le militantisme visant à concevoir pour innover en n'omettant pas de partir des besoins et cultures humaines. C'est sans doute ce qui fonde une culture technique.

Bruno Jacomy aborde la question de la culture technique à l'heure du numérique. L'auteur plaide pour une promotion de la culture technique, qui lui semble aujourd'hui, primordiale alors que le numérique bouleverse nos habitudes. Bruno Jacomy insiste sur la nécessité d'une culture technique pour tous qui ne doit pas rester cantonnée aux seuls professionnels de la technique. Pour asseoir sa définition, il repart de celles de Philippe Roqueplo et de Joël Lebaume. Ce dernier distinguait au XIX ${ }^{\mathrm{e}}$ siècle trois facettes à la culture techniques : celle de la main - le travailleur (ingénieur, artisan, ouvrier), celle de l'esprit - l'homme qui maîtrise son environnement grâce aux objets techniques qu'il conçoit et celle du cœur - le citoyen qui fait des choix à travers une dimension critique et culturelle assignée aux objets. Bruno Jacomy insiste sur le fait que ces trois dimensions doivent être requestionnées au regard de l'importance du numérique dans nos vies quotidiennes. En effet, les objets issus du numérique marquent une rupture importante dans notre environnement quotidien: la technique étant plus que jamais au cœur de notre vie car la communication reste un élément central de notre monde actuel. A travers ce texte, Bruno Jacomy questionne aussi l'innovation comme processus social et culturel. Il nous invite à adopter une approche généalogique des objets comme Gilbert Simondon et Yves Deforge le préconisaient. Ce mode de pensée nous aide à comprendre les familles d'objets - comme celles exposées dans les musées - et à en tirer de la créativité. Les objets portent en eux la mémoire de la société et des savoirs techniques mobilisés.

Si l'on accepte de considérer la relation de la culture d'innovation à la capacité à innover des organisations on est rapidement conduit, dans une logique de management de l'innovation, à s'interroger sur les facteurs clés d'une telle culture. C'est précisément le point de départ de la contribution de Muriel Davies et Stéphanie Buisine. L'objectif de leur contribution n'est en effet pas de définir ce que l'on entend par culture d'innovation mais d'identifier les ingrédients d'une telle culture dans les organisations. Partant d'un survey de la littérature et d'une conception de la culture d'innovation dans les organisations comme la part de la culture d'une organisation en lien avec l'innovation, les auteurs esquissent les contours d'un modèle de culture d'innovation. Ce modèle identifie cinq facteurs clés, à savoir la présence de dirigeants et managers innovants, la présence et la valorisation d'équipes innovantes, la présence d'individus innovants, un contexte organisationnel favorable à l'innovation et, pour finir des liens avec l'extérieur de l'organisation. Le modèle proposé par les auteurs est extrêmement intéressant car s'il présente de possibles leviers d'action pour améliorer la capacité effective des organisations à innover, il montre clairement l'absence de la «dimension culturelle » dans ce que l'on qualifie couramment de culture d'innovation dans les organisations.

Dans la dernière contribution de ce numéro, John Didier part du constat selon lequel l'enseignement des disciplines techniques dispense un rapport à l'objet en rupture avec sa genèse et son devenir ce qui contribue à alimenter la représentation de l'objet technique sans culture. Afin de remédier à cette situation, il propose de transformer le rapport à la culture technique en formant des concepteurs. Est alors présenté le modèle didactique Conception-Réalisation-Socialisation. Ce dernier est destiné à former des concepteurs capables d'identifier, de comprendre et de concevoir des objets techniques porteurs de durabilité, conçus avec intelligibilité dans une dynamique prospective et durable. Pour ce (c) 2017 ISTE OpenScience - Published by ISTE Ltd. London, UK - openscience.fr 
faire, le modèle Conception-Réalisation-Socialisation propose d'utiliser la conception comme outil de changement et d'apprentissage en vue de développer une culture de l'innovation raisonnée, réfléchie et adaptée aux besoins de l'usager et de la société. A suivre John Didier, ce modèle fournirait les clés pour passer d'une production d'innovations incrémentales à celle d'innovations radicales orientées vers un progrès durable. 